\title{
A Literature Review of Bimodal Fitting
}

\author{
Junghwa Bahng ${ }^{1,2}$, Soo Hee Oh',2 \\ 'Department of Audiology and Speech-Language Pathology, Hallym Univesity of Graduate Studies, Seoul, Korea \\ ${ }^{2}$ HUGS Center for Hearing and Speech Research, Hallym University of Graduate Studies, Seoul, Korea
}

Received: June 27, 2020
Revised: July 28, 2020
Accepted: August 7, 2020
Correspondence:
Soo Hee Oh, PhD
Department of Audiology and
Speech-Language Pathology,
Hallym Univesity of Graduate Studies,
427 Yeoksam-ro, Gangnam-gu,
Seoul 06197, Korea
Tel: +82-70-8680-6901
Fax: +82-2-3453-6618
E-mail: osh503@naver.com

E-mail: osh503@naver.com
Although there are quite a few bimodal cochlear implant users, bimodal fitting guidelines were not fully developed. Bimodal fitting optimization is one of the factors that contribute to successful bimodal outcomes. The purpose of this study is to investigate recent literatures related to bimodal fitting to establish evidence based bimodal fitting guidelines. Three databases including Google Scholar, PubMed publisher, and PLOS One were searched to review bimodal fitting literatures. A total of 599,604 articles were identified by using ten bimodal relevant keywords at the initial stage. Then, we included 192 articles with abstract review, inclusion and exclusion criteria and removals of duplicates. Lastly, two authors reviewed full texts and identified a total of 19 bimodal fitting articles. Results were categorized into type of bimodal intervention, procedures, and outcomes. Bimodal fitting procedures, test materials, and questionnaires were also summarized. A total of 18 articles consist of bimodal hearing aid fitting covering hearing aid fitting formula, gain adjustment, loudness balance, frequency band, frequency lowering technology, and overall bimodal fitting guidelines. Only one article includes bimodal cochlear implant fitting with low frequency band adjustment. Several factors including real-ear measurement, loudness balance test, frequency band selection considering cochlear dead region, and subjective questionnaires are considered to optimize bimodal hearing aid fitting. Bimodal fitting guidelines considering several relevant factors will optimize bimodal fitting and improve bimodal benefits.

Key Words: Bimodal fitting, Bimodal hearing, Hearing aid fitting.

\section{INTRODUCTION}

인공와우는 난청인의 와우 기능을 대신하는 청각기기로 와 우에 이식된 전극의 활성을 통해 나선신경절세포(spiral ganglion cell) 또는 청신경에 직접 전기자극을 전달하여 청지각을 회복시키는 장치이다. 보청기가 음향자극의 증폭을 통해 외이 에서 내이를 거처 증폭된 소리를 전달하고 대뇌청각피질에서 소리를 인지하도록 한다면 인공와우는 음향자극을 전기자극으 로 바꾸어 이를 직접 내이에 전달하여 소리를 인지하도록 한 다. 인공와우는 지금까지 말지각 측면에서 상당한 효과가 보고 되었으나(Gifford et al., 2010; Spahr et al., 2012) 소음 상황과 음악지각 등에서의 어려움(Gfeller et al., 2012; Müller et al., 2012)은 여전히 남아 있으며, 이는 인공와우의 전기적 신호처리 의 한계(Kong et al., 2004; Shannon et al., 1995)와 밀접한 연 관성이 있는 것으로 알려져 있다.

(cc) This is an Open Access article distributed under the terms of the Creative Commons Attribution Non-Commercial License (https://creativecommons.org/licenses/by-nc/4.0) which permits unrestricted non-commercial use, distribution, and reproduction in any medium, provided the original work is properly cited.
최근 저주파수 잔존 청력이 어느 정도 남아 있는 경우에도 인공와우 수술을 받을 수 있도록 인공와우 대상자 기준이 확 대되었고(Gifford et al., 2010; UK Cochlear Implant Study Group, 2004) 인공와우와 보청기를 동시에 착용하는 청각기기 의 활용 사례가 증가하는 추세이다. 이 중 바이모달 청각 $\left(\mathrm{bi}^{-}\right.$ modal hearing)은 잔존 청력을 활용하기 위하여 인공와우를 착용한 반대편 귀에 보청기를 착용하는 형태이다. 선행연구에 서는 조용한 상황과 소음 환경에서의 말지각과 음악지각 등 여 러 측면에서 바이모달 청각의 긍정적 효과(Dorman et al., 2008; McDermott, 2011)를 보고하였고 이는 기본 주파수(fundamental frequency)와 제1 포먼트(formant 1)와 같은 말소리 단서의 보완과 밀접한 관련이 있는 것으로 설명하였다(Kong \& Carlyon, 2007). 바이모달 청지각의 효과는 연구에 따라 다양 한 차이를 보이는데 음조위상의 불일치(tonotopic mismatch), 잔존 청력 정도, 양이 융합(binaural fusion), 최적화되지 않은 바이모달 적합, 소리 크기의 불균형 등이 이러한 결과에 영향을 미치는 요인으로 추측된다(Veugen et al., 2016b). 특히 바이모 달 적합 지침의 필요성과 관련하여 Vroegop et al.(2018)은 인 
공와우 착용 성인의 절반 이상이 바이모달 사용자로 바이모달 착용 효과를 향상시킬 수 있는 바이모달 적합 지침의 필요성을 강조하였다.

현재 주요 인공와우 제조사에서 바이모달 적합 지침을 제공 하고 있으나(Advanced Bionics, 2014; Cochlear ${ }^{\mathrm{TM}}$, 2012; Oticon, 2016) 바이모달 적합의 최적화를 위한 증거기반의 연구와 지침은 아직까지 부족하고 실제 임상에서는 센터마다 각각의 방 법으로 바이모달 적합을 시행하고 있다(Siburt \& Holmes, 2015). 바이모달 적합의 최적화를 위해서는 먼저 적절한 적합 지침과 평가 프로토콜이 확립되어야 하며, 최적화된 바이모달 프로그 램의 사용은 바이모달 착용 효과 및 만족도 향상에 기여할 뿐 아니라 양이 인공와우 대상자 결정에 필요한 정보를 제공할 수 있을 것이다.

바이모달 적합은 일반적으로 인공와우 적합, 보청기 적합, 인 공와우와 보청기 두 개 청각기기 간 적합을 포함한다. 기존 바 이모달 적합 연구에서는 인공와우 적합보다는 보청기 적합과 관련된 내용을 주로 다루었고, 두 개 청각기기 간 적합과 관련 하여 양 귀 간 소리 크기의 균형을 확립하기 위한 적합 방법을 보고하였다(Ching et al., 2004). 최근 바이모달 보청기 적합에 대한 체계적 문헌 고찰(Vroegop et al., 2018)에서 보청기 적합 시 광대역 주파수의 적용, 보청기 주파수 변이 또는 압축 방식 의 활용 효과, 보청기와 인공와우의 양 귀 간 역동압축의 일치, 음량평형을 고려한 보청기 이득조절과 양귀 간 소리 크기 균형 효과와 관련된 내용을 보고한 바 있다. 그러나 바이모달 인공 와우 적합에 대한 내용은 제외하였고 실제 활용할 수 있는 바 이모달 적합 및 바이모달 평가 방법에 대한 세부적인 내용은 포함하지 않았다. 증거기반의 바이모달 적합 체계를 확립하고 활용하기 위해서 기존에 보고된 인공와우와 보청기를 포함하 는 바이모달 적합의 내용과 방법, 평가 방법과 도구에 대한 분 석이 선행되어야 하며 이를 근거로 활용 가능한 바이모달 적합
연구가 진행되어야 할 것이다.

본 연구의 목적은 2019년 9월까지 보고된 바이모달 적합 문 헌에 대한 체계적인 고찰을 시행하여 기존 연구에서 제시한 보 청기와 인공와우를 포함하는 바이모달 적합 방법, 평가 내용 및 도구를 분석하는 것이다. 이를 근거로 바이모달 적합의 최적화 를 위한 적합 및 평가 방법을 파악하고 바이모달 적합 지침과 바이모달 평가 프로토콜 확립의 기초 자료를 확보하고자 한다.

\section{MATERIALS AND METHODS}

본 연구에서는 PubMed publisher, Google Scholar, PLOS One 3 개의 데이터 베이스를 활용하여 바이모달 적합 문헌을 검색하고 2019년 9월까지 보고된 문헌을 분석하였다. 문헌 검 색의 방법과 절차는 Preferred Reporting Items for Systematic Review (Moher et al., 2015) 지침을 참고하였고 연구에서 시행한 전반적인 문헌 검색 절차는 Figure 1 과 같다. 1 단계 문 헌 검토에서는 10 개의 중심단어(bimodal hearing, bimodal hearing aid, bimodal cochlear implant, bimodal benefit, bimodal programming, bimodal fitting, bimodal mapping, electric-acoustic hearing, fitting, contralateral fitting)로 검색 하여 3 개의 데이터 베이스에서 총 599,604개의 문헌을 추출하 였다. 2 단계에서는 바이모달 적합 관련 문헌 선정을 위해 실제 바이모달 사용자 대상의 바이모달 적합과 적합 효과에 관한 연 구만을 본 연구에 포함하도록 하였다(Table 1). 한 명의 검토자 가 Table 1의 문헌 포함 기준과 제외 기준을 적용하여 논문 제 목과 초록을 검토한 뒤 중복 문헌을 제외하고 최종 192개의 문 헌을 선정하였다. 3 단계에서는 본 연구의 저자 2 명이 2 단계에서 정리된 192개 문헌을 각각 검토하였고, 바이모달 적합과 그 효 과에 대한 내용 여부를 확인하여 1차로 37 개의 논문을 결정한 뒤, 두 저자 간 일치하지 않았던 논문의 내용을 2차 검토하여

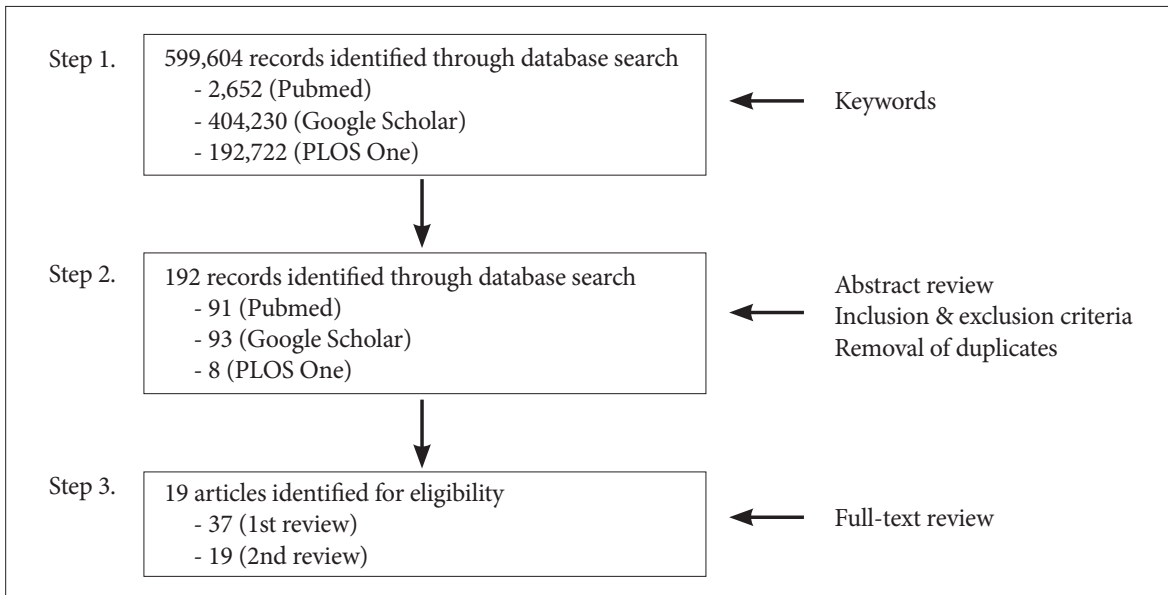

Figure 1. Flowchart of the systematic review of bimodal fitting literature. 
Table 1. Inclusion and exclusion criteria of this study

\begin{tabular}{ll}
\hline \multicolumn{1}{c}{ Inclusion criteria } & \multicolumn{1}{c}{ Exclusion criteria } \\
\hline Studies of bimodal fitting \& & Studies of not bimodal fitting \& \\
fitting outcomes & fitting outcomes \\
Real bimodal users & Bimodal simulation studies \\
English articles & Review papers, abstracts, theses \\
& Non English articles \\
\hline
\end{tabular}

최종 19 개의 바이모달 적합 관련 논문을 결정하였다(Figure 1). 최종 선정된 19 개 논문을 검토하고 바이모달 적합 지침 확 립을 위해 본 연구의 관심 항목인 적합 주제, 적합 방법, 평가 도구, 평가 항목, 결과 등으로 구분하여 정리하였다.

\section{RESULTS}

Table 2 는 총 19 개 바이모달 적합 관련 논문의 내용을 적합 중재, 적합 내용, 검사 방법 및 도구, 결과, 설문지 항목으로 정 리한 결과이다. 19 개 문헌 중 바이모달 인공와우 적합 논문은 1 개였고 나머지 18 개 논문 모두 바이모달 보청기 적합에 대한 내용을 포함하여, 바이모달 적합 관련 연구가 대부분 보청기 적합 주제로 진행되고 있음을 확인하였다. 바이모달 보청기 적 합과 관련된 18 개 연구의 주요 중재 내용은 1) 보청기 적합공 식, 2) 보청기 이득조절, 3) 양 귀 간 음량평형, 4) 보청기 주파수 범위, 5) 보청기 주파수 변이 시스템, 6) 바이모달 적합 프로토 콜에 대한 6 개의 카테고리로 구분되었다. 한편 바이모달 인공 와우 적합에 대한 1 개 논문에서는 인공와우 저주파수 대역의 조절에 따른 바이모달 효과를 포함하고 있었다. 다음에서는 바 이모달 적합과 관련된 19 개 문헌의 대략적 내용을 설명하였고 Table 2에서 각 연구의 구체적인 내용을 확인할 수 있다.

\section{바이모달 적합에서의 보청기 적합공식}

바이모달 적합에서 각각 다른 보청기 적합공식의 적용에 따 른 결과를 비교한 연구(Cuda et al., 2019; English et al., 2016; Vroegop et al., 2019)에서는 바이모달 보청기 적합공식인 Adaptive Phonak Digital Bimodal (APDB)과 일반적인 보청기 적합공식인 Desired Sensation Level version 5, National Acoustics Laboratories Non-Linear version 2(NAL-NL2)를 비교하였다. 결과적으로 각 보청기 적합공식에 따른 말지각 측 면에서 의미 있는 차이는 보이지 않았다. NAL-NL2와 보청기 자체의 적합공식을 사용한 결과를 비교했을 때에도 말지각에 서 차이를 보이지 않아 보청기 적합공식의 차이가 바이모달 말 지각 결과에 큰 영향을 미치지 않는 것으로 나타났다. 다만, 적 합공식의 선호도를 조사한 결과 APDB와 NAL-NL2를 다른 적합공식보다 좀 더 선호하는 것으로 나타났다. 이러한 결과는
사용자는 말지각의 측면보다는 주관적인 소리의 질 등으로 보 청기 적합공식을 선호함을 보여주었다.

\section{바이모달 적합에서의 보청기 이득조절}

보청기 이득조절 및 음량평형과 관련된 연구(Ching et al., 2004; Harris \& Hay-McCutcheon, 2010; Veugen et al., 2016a, 2016b; Yehudai et al., 2013)를 살펴보면, 압축 채널의 수와 시 간 측면에서 보청기의 자동이득조절(automatic gain control) 조건을 인공와우의 자동이득조절 조건과 매치했을 때 매치하 지 않았을 때보다 말지각에서 향상된 결과를 보여, 보청기와 인공와우 두 개 청각기기 간 자동이득조절 조건을 동일하게 했 을 때 바이모달 결과 향상에 영향을 미칠 수 있음을 보여주었 다(Veugen et al., 2016b). 또한 바이모달 보청기 적합에서 보청기 의 이득은 실이측정의 목표 이득에 미치지 못하는 것으로 나타 났으나(Ching et al., 2004; Harris \& Hay-McCutcheon, 2010; Yehudai et al., 2013), 기능이득 결과에서는 보청기 착용 후 저 주파수 대역에서 다른 주파수 대역보다 이득이 많음을 보였다. 또한 보청기 착용 후 역치 평가가 바이모달 결과가 좋은 사용 자와 그렇지 못한 사용자 간의 차이를 보이지 않아(Harris \& Hay-McCutcheon, 2010) 기능이득만으로 바이모달 보청기 적 합의 최적화를 확인하는 데에는 한계가 있을 것으로 보여진다.

\section{바이모달 적합에서의 양 귀 간 음량평형}

양 귀 간 음량평형 연구와 관련하여 Veugen et al.(2016a)은 광대역 주파수 대역에 근거한 음량평형 방법과 3개 주파수 밴 드로 구분한 주파수 의존적 음량평형 방법을 적용하여 보청기 이득을 조절하고 바이모달 효과를 비교했을 때, 광대역 또는 주파수 의존적 음량평형에 따른 말지각 결과에 차이가 없었다 (Veugen et al., 2016a). Table 2에 보고된 대부분의 연구에서 바이모달 적합 시 인공와우와 보청기의 음량평형을 적용하였 으며, 예를 들어 Ching et al.(2004)의 연구에서는 처음에는 인 공와우만 착용한 상태에서 녹음된 이야기를 듣도록 하고 인공 와우와 비교하여 보청기가 동일한 소리 크기로 들릴 수 있도록 보청기의 이득을 조절하는 음량평형 방법을 제시하였다

\section{바이모달 적합에서의 주파수 범위}

바이모달 보청기 적합의 주파수 대역 설정에 따른 효과를 비교 했을 때(Messersmith et al., 2015; Neuman \& Svirsky, 2013; Neuman et al., 2019) 대부분의 연구에서 보청기 주파수 대역 설정에 따른 결과의 차이가 없었으며, 바이모달 보청기 적합에 서 광대역 주파수의 우선적 적용이 가능함을 보여주었다. Messersmith et al.(2015)의 연구에서는 전기와 음향 자극 주파수 대 역의 중복을 제한하고 와우 사영역(dead region)을 고려하여 


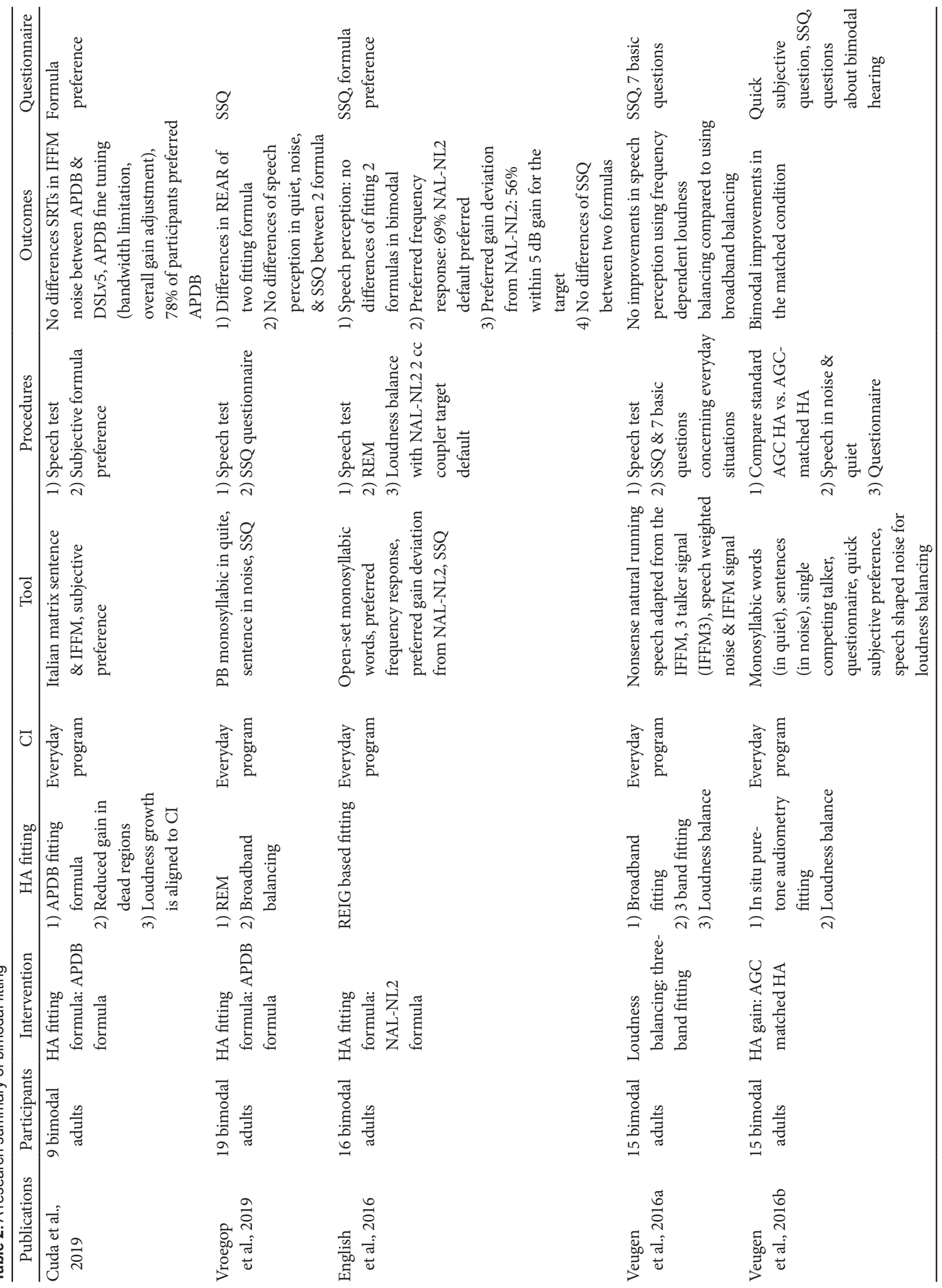




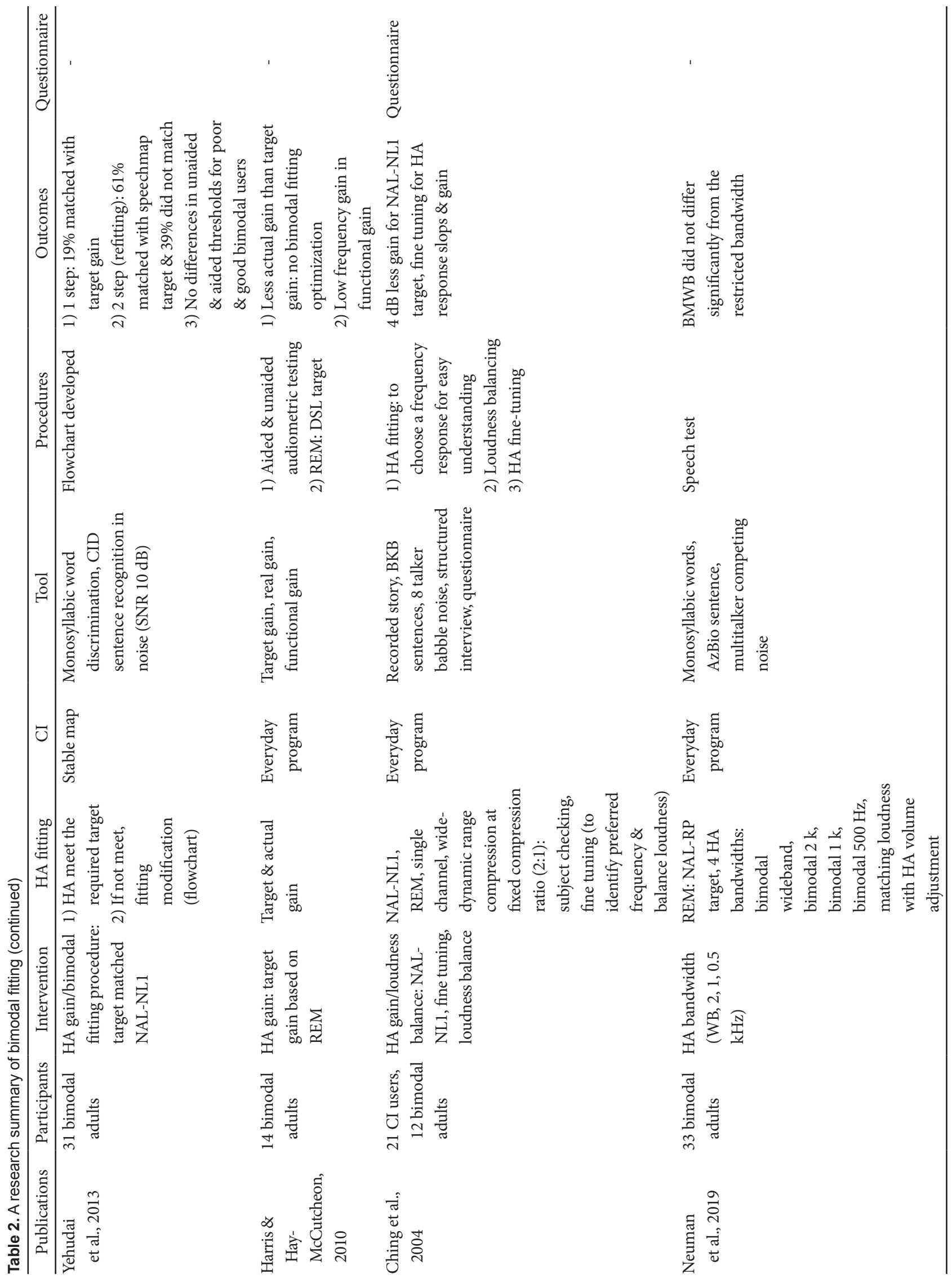




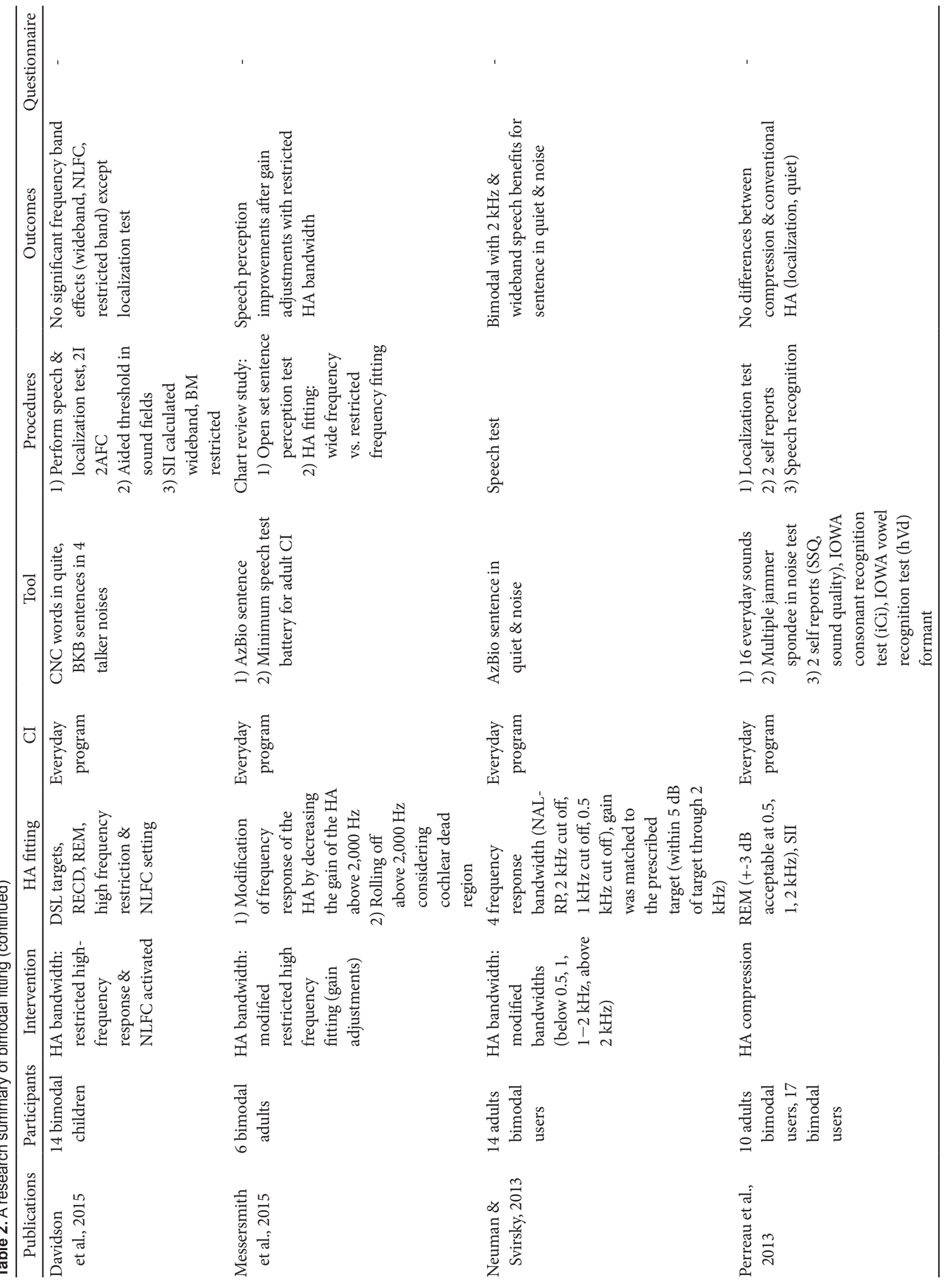




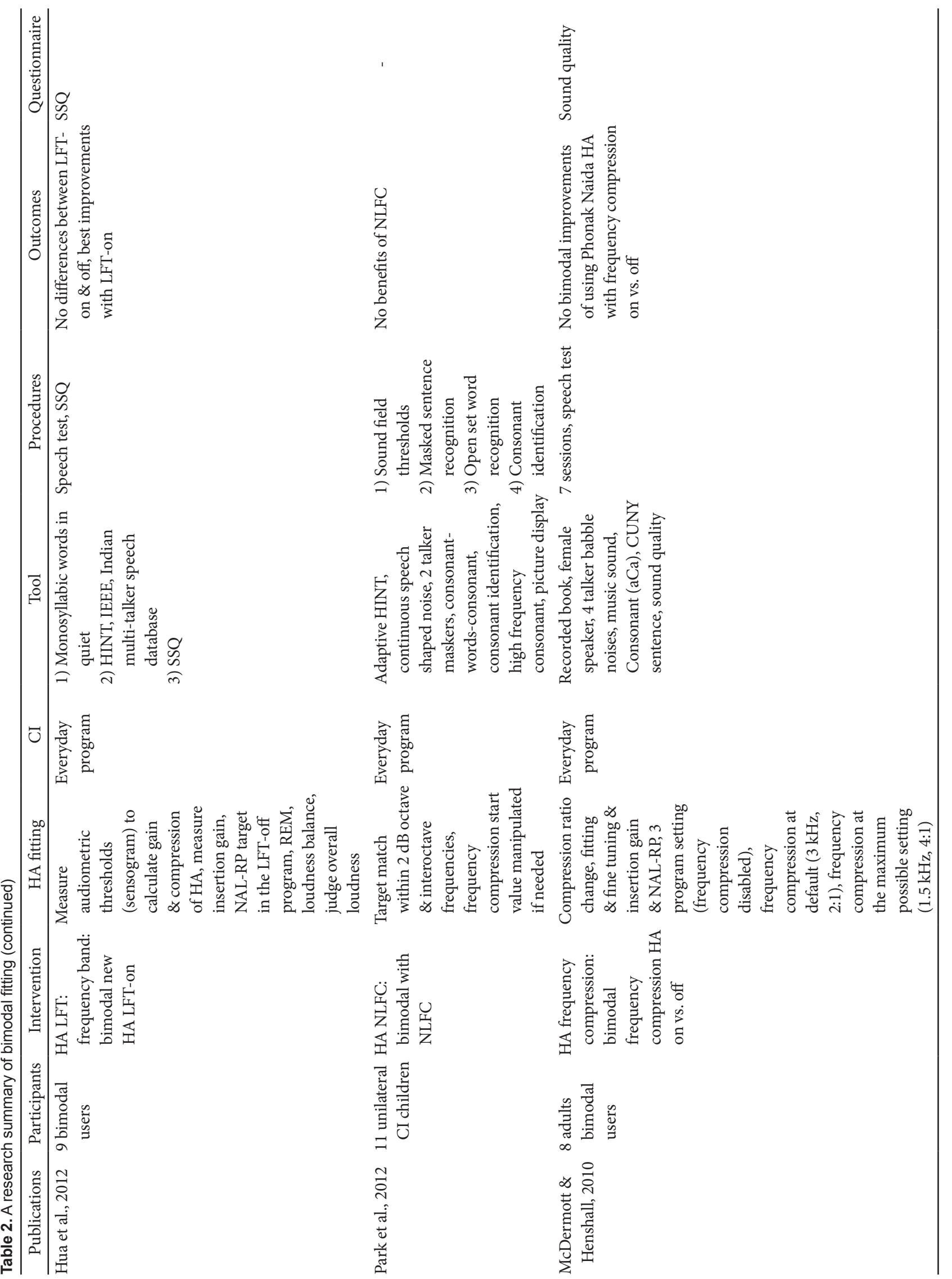




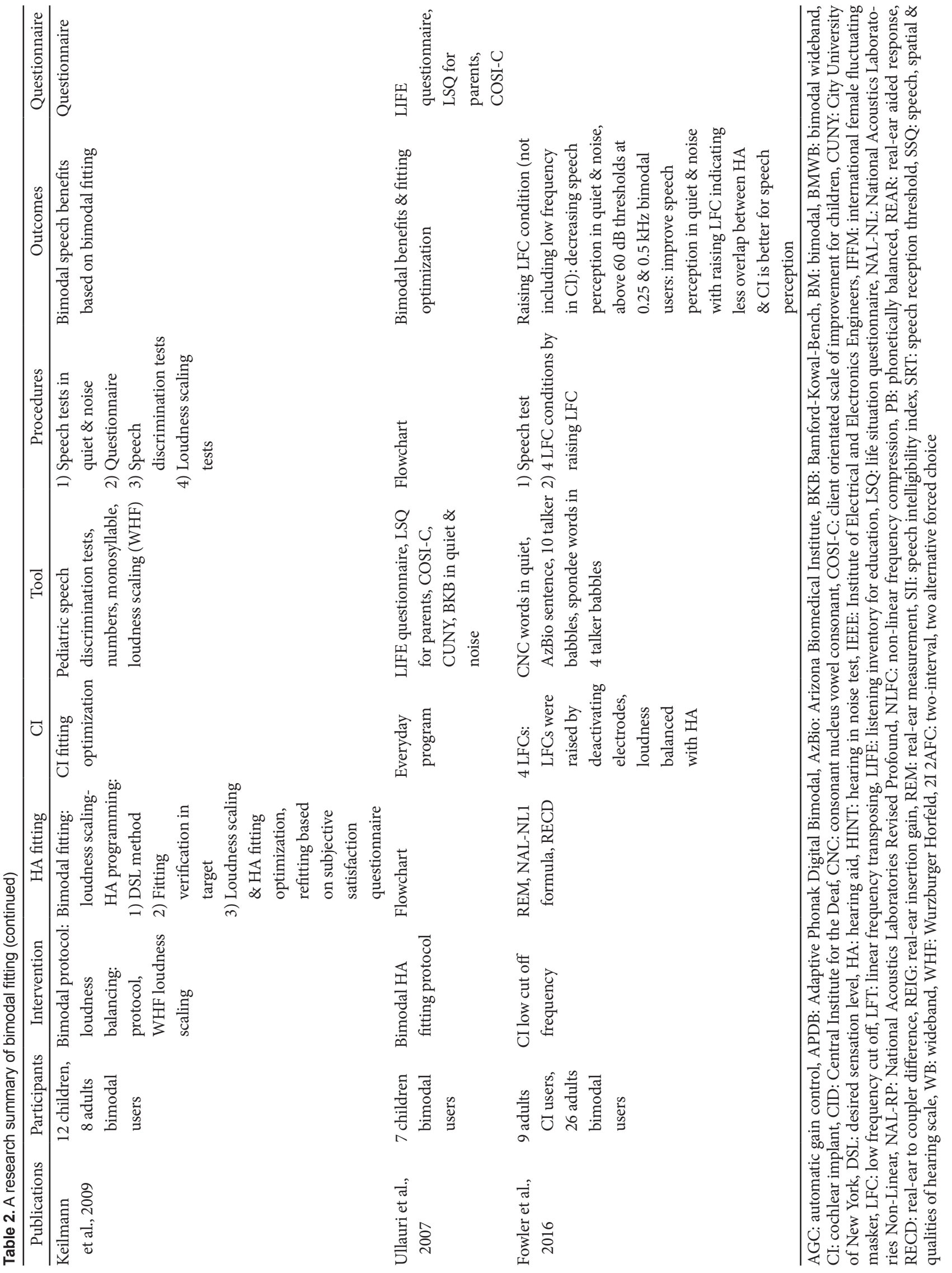


$2,000 \mathrm{~Hz}$ 이상 주파수의 보청기 이득을 옥타브당 $12 \mathrm{~dB}$ 의 비 율로 감소시켰을 때 바이모달 말지각의 향상을 보고하였고, Neuman \& Svirsky(2013)의 연구에서도 광대역 주파수의 적용 과 $2,000 \mathrm{~Hz}$ 이상 주파수 대역을 제한한 경우 모두 소음과 조 용한 상황의 문장 검사에서 향상을 보였다.

바이모달 인공와우 적합 연구(Fowler et al., 2016)에서는 인 공와우의 저주파수 대역과 보청기 저주파수 대역이 서로 중복 되지 않도록 청력 역치를 고려하여 인공와우 저주파수 대역을 상향 조정했을 때 소음과 조용한 상황에서 말지각이 향상됨을 보여주었고, 이는 반대편 귀의 청력 역치에 따른 인공와우의 저 주파수 대역 조절의 가능성을 보여주었다.

\section{바이모달 적합에서의 보청기 주파수 변이 시스템}

Davidson et al.(2015)은 비선형 주파수 압축(non-linear frequency compression, NLFC), 광대역 주파수 또는 제한된 주파수 대역을 적용한 효과를 비교했을 때 소음하 조건과 조 용한 상황 조건에서의 말지각 검사 결과에는 영향이 없음을 보 고하였다. 그러나 방향성 검사에서는 바이모달의 광대역 주파 수와 NLFC 조건에서 인공와우만 착용했을 때보다 의미 있는 향상을 보였다. 보청기의 주파수 압축을 포함하는 주파수 변이 시스템의 적용 효과를 연구한 다른 연구(Davidson et al., 2015; Hua et al., 2012; McDermott \& Henshall, 2010; Park et al., 2012; Perreau et al., 2013)에서도 보청기의 주파수 압축 시스 템의 적용이 바이모달 결과 향상에 영향을 미치지 않는 것으로 나타났다.

\section{바이모달 적합에서의 보청기 적합 프로토콜}

바이모달 적합 절차와 방법에 대한 연구(Keilmann et al., 2009; Ullauri et al., 2007; Yehudai et al., 2013)에서는 바이모 달 적합을 위한 전반적인 지침과 방법을 기술하고 그 효과를 보여주었다. 연구에서 제시한 바이모달 프로토콜의 내용은 적 절한 보청기 이득의 설정, 양 기기 간 음량평형, 실이측정에 근 거한 적합과 적합 확인 및 전반적인 바이모달 평가 프로토콜의 도식을 포함하고 있으며 이러한 바이모달 적합 지침의 적용이 적합의 최적화와 결과 향상에 기여함을 보고하였다.

\section{DISCUSSIONS}

본 연구에서는 바이모달 적합 문헌에 대한 체계적인 고찰을 시행하여 증거기반의 바이모달 적합 지침 확립을 위한 기초 자 료로 활용하고자 하였다. 총 19 개 바이모달 적합 관련 연구를 검토한 결과 바이모달 보청기 적합공식, 보청기 이득조절, 음량 평형, 보청기 주파수 범위, 주파수 변이 시스템, 바이모달 적합
프로토콜에 대한 연구 및 바이모달 인공와우 적합에 대한 내 용을 확인하였다. 또한 여러 문헌에서 제시한 바이모달 적합, 평가 방법과 도구 및 결과에 대한 내용을 요약하였다.

바이모달 보청기 적합과 관련하여 몇 가지 주요 내용을 정리 하면 기존의 다양한 보청기 적합공식의 적용이 가능하고(Cuda et al., 2019; English et al., 2016; Vroegop et al., 2019), 실이측 정에 근거한 보청기 이득조절, 예를 들어 보청기의 목표 이득과 실제 조절 이득은 $5 \mathrm{~dB}$ 이내의 편차로 조절하여야 하는 등의 적합확인(Neuman \& Svirsky, 2013; Neuman et al., 2019)이 병행되어야 한다. 보청기 주파수 범위는 광대역 주파수를 우선 적으로 적용할 수 있으나 청력 또는 와우 사영역 존재 여부에 따라 고주파수 대역, 예를 들어 $2,000 \mathrm{~Hz}$ 이상의 이득을 감소 시킬 수 있다(Messersmith et al., 2015). 또한 대부분의 연구에 서 보청기 이득조절을 통한 양 귀 간 음량의 평형을 고려하였 으며 보청기 미세 조정이 결과 향상에 좀 더 기여할 수 있는 것 으로 나타났다(Ching et al., 2004). 바이모달 적합에서 인공와 우는 일상에서 사용하는 프로그램을 주로 활용하였고 안정적 인 매핑 상태에서 보청기 적합을 시행한 것으로 나타났다(Keilmann et al., 2009; Yehudai et al., 2013). 바이모달 결과 측정을 위한 평가 도구는 소음과 조용한 상황에서의 다양한 말지각 검 사(음소, 일음절, 단어, 문장)를 시행하였고 방향성 검사와 주 관적 선호 및 설문 검사(Keilmann et al., 2009; Veugen et al., 2016a, 2016b)를 추가적으로 수행하였다. 주관적 설문 검사는 언 어 공간 음질 청취 평가(speech, spatial \& qualities of hearing scale) (Gatehouse \& Noble, 2004), 보청기 적합 선호도 검사, 일상 생활과 관련된 질문, 청취 음질과 편안함에 대한 질문, 바 이모달 사용 및 효과 관련 질문 등 여러 설문 내용을 포함하였 다. 결과 측정 방법은 연구마다 차이가 있으나 음장에서 약 1 $\mathrm{m}$ 거리 정면에 위치한 스피커를 통해 신호(예를 들어 55 65 $\mathrm{dB}$ SPL 강도의 말소리)를 제시하는 방식(English et al., 2016; Neuman \& Svirsky, 2013)으로 측정하였으며, 검사의 목적에 따라 스피커의 개수와 위치 등의 조건을 조정하였고 소음의 종 류 및 제시 방향도 연구에 따라 차이가 있었다(Table 2).

본 연구의 결과를 토대로 바이모달 적합 과정 및 평가 요소 를 정리하면 다음과 같다. 먼저 바이모달 사용자를 대상으로 순음과 어음 청력 검사 및 말지각 검사를 시행한다. 인공와우 매핑의 안정성 확보, 주파수 범위 확인 및 인공와우 착용 후 청 력검사를 통해 인공와우의 적절한 적합 상태를 확인한다. 또한 보청기 적합의 경우 보청기 적합공식의 선택, 실이측정과 음량 평형에 근거한 이득조절 및 미세 조정을 시행하고 와우 사영역 검사를 근거로 보청기 증폭의 주파수 대역을 결정한다. 인공와 우와 보청기를 착용한 양 귀 간 음량의 평형을 맞추기 위한 검 사를 시행하고, 일반적으로 인공와우를 기준으로 보청기의 전 
반적인 음량이나 이득을 조절하는 방법을 적용한다. 바이모달 적합 효과 측정을 위해 말지각 검사, 기능이득 검사, 실이측정, 방향성 검사와 주관적 설문 검사를 수행하여 바이모달 적합을 확인하고 그 이득을 측정한다. 바이모달 이득의 정도에 따라 사용자의 만족도 및 그 효과를 확인할 수 있으며 바이모달로 인한 이득이 부재하거나 만족도가 낮은 경우 양이 인공와우 대 상자로 고려할 수 있다. 이러한 방법은 바이모달 적합 지침 확 립에 활용 가능하고 바이모달 적합의 최적화와 만족도 및 결과 향상에 기여할 수 있을 뿐 아니라 양이 인공와우 대상자 선별 에 도움이 될 수 있을 것으로 생각한다.

바이모달 적합의 최적화와 관련하여 Gifford(2019)는 와우 사영역 검사 결과와 보청기 주파수 대역과의 관계를 좀 더 뒷 받침할 수 있는 바이모달 적합 연구와 음량평형에 근거한 보청 기의 이득조절이 바이모달 말지각 향상에 미치는 영향에 대한 추가적 연구가 필요함을 언급하였다. 본 문헌 고찰에서는 바이 모달 적합에서 와우 사영역 검사를 근거로 한 주파수 대역 설정 과 이득조절(Messersmith et al., 2015)의 효과를 확인하였다. Zhang et al.(2014)의 연구에서는 바이모달 사용자의 보청기 적 합에서 와우 사영역 검사 결과를 반영하여 보청기 주파수 대역 을 결정했을 때, 바이모달 이득이 향상되었고 바이모달 적합에 서 와우 사영역 검사의 필요성을 보고한 바 있다. 바이모달 사 용자의 경우 고주파수 청력이 저주파수 잔존 청력에 비해 많이 떨어지는 경우가 많은데 이때 주파수별 와우 사영역 검사를 시 행하여 보청기의 주파수 대역 조절에 참고할 수 있다. 이는 보 청기 착용귀의 사영역 주파수를 증폭하지 않도록 하여 보청기 와 인공와우 주파수 대역의 중복을 감소시키는 효과도 있을 것 이다(Fowler et al., 2016). 또한 Gifford(2019)가 제시한 음량평 형에 근거하여 보청기 이득을 조절한 경우 말지각에 어떤 영향 을 미치는지에 대한 연구와 함께, 현재 일반적으로 실행되는 보 청기 중심의 음량평형 검사 방법에 대한 연구뿐만 아니라 인공 와우의 음량평형을 맞추기 위한 방법적 연구도 필요할 것이다.

기존 바이모달 적합 연구 결과에서 각기 다른 보청기 적합공 식의 적용이나 주파수 변이 시스템의 적용 효과는 없었으나, 실 이측정과 미세 조정을 통한 목표 이득에 근접한 적절한 주파수 이득의 설정은 바이모달 이득 향상에 효과가 있었다. 또한 인공 와우와 보청기의 자동이득조절(automatic gain control) 압축 특징이 서로 다르기 때문에 이를 매치할 수 있는 바이모달 시 스템의 개발도 바이모달 결과 향상에 긍정적 영향을 미칠 수 있을 것으로 생각된다. 마지막으로 바이모달 적합 시 주관적인 선호와 이득을 측정할 수 있는 적절한 주관적 평가 도구에 대 한 검토가 필요할 것이다.

바이모달 적합과 평가 프로토콜을 위한 기초 구성 요인을 파 악하기 위하여, 본 연구에서는 연구의 주요 관심 영역인 바이모

달 적합과 평가 방법 및 결과를 분석하였고 검토 문헌의 질에 대한 평가는 시행하지 않았으며 이는 본 연구의 한계점이라 할 수 있다. 그러나 기존 연구를 근거로 실제 적용 가능한 바이모 달 적합과 평가 방법을 보고했다는 측면에서 긍정적 의미가 있 으며 향후 바이모달 적합의 각 구성 요인과 관련된 후속연구를 진행하여 증거기반의 바이모달 적합 지침과 평가 프로토콜이 확립될 수 있기를 기대한다.

중심 단어 : 바이모달 적합·바이모달 청각·보청기 적합.

\section{Ethical Statement \\ N/A}

\section{Acknowledgments}

The authors thanks to Myounghwa Lee who supported data search. Also, thanks to the National Research Foundation of Korea sponsored the research project.

\section{Declaration of Conflicting Interests}

There are no conflict of interests.

\section{Funding}

This work was supported by the Ministry of Education of the Republic of Korea and the National Research Foundation of Korea (2019S1A5A 8038153).

\section{Author Contributions}

S.O. designed and performed experiments, analyzed data, and wrote the paper; J.B. designed, analyzed data, and wrote the paper; S.O. and J.B. provided statistical analysis and critical revision. Also, the authors discussed the results together and implications and commented on the manuscript at each stage.

\section{ORCID iDs}

Junghwa Bahng

Soo $\mathrm{Hee} \mathrm{Oh}$

\author{
https://orcid.org/0000-0002-5265-3586 \\ https://orcid.org/0000-0002-3745-1484
}

\section{REFERENCES}

Advanced Bionics. (2014). Bimodal Fitting Quick Guide. Retrieved from http://www.onici.be/userfiles/files/028-M384-02_Global\%20A4\%20Bimodal\%20Fitting\%20Guidelines\%20for\%20Professionals\%20JUN09_ FINAL.pdf.

Ching, T. Y. C., Incerti, P., \& Hill, M. (2004). Binaural benefits for adults who use hearing aids and cochlear implants in opposite ears. Ear and Hearing, 25(1), 9-21.

Cochlear $^{\mathrm{TM}}$. (2012). Bimodal Hearing: A Guide to Fitting. Retrieved from https://www.onici.be/userfiles/files/Bimodal-Hearing-A-Guide-to-Fitting.pdf.

Cuda, D., Murri, A., Mainardi, A., \& Chalupper, J. (2019). Effectiveness and efficiency of a dedicated bimodal fitting formula. Audiology Research, 9(1), 219.

Davidson, L. S., Firszt, J. B., Brenner, C., \& Cadieux, J. H. (2015). Evaluation of hearing aid frequency response fittings in pediatric and young adult bimodal recipients. Journal of the American Academy of Audiology, 26(4), 393-407.

Dorman, M. F., Gifford, R. H., Spahr, A. J., \& McKarns, S. A. (2008). The benefits of combining acoustic and electric stimulation for the recognition of speech, voice and melodies. Audiology and Neurotology, 13(2), 
105-112.

English, R., Plant, K., Maciejczyk, M., \& Cowan, R. (2016). Fitting recommendations and clinical benefit associated with use of the NAL-NL2 hearing-aid prescription in Nucleus cochlear implant recipients. International Journal of Audiology, 55(Suppl 2), S45-S50.

Fowler, J. R., Eggleston, J. L., Reavis, K. M., McMillan, G. P., \& Reiss, L. A. (2016). Effects of removing low-frequency electric information on speech perception with bimodal hearing. Journal of Speech, Language, and Hearing Research, 59(1), 99-109.

Gatehouse, S. \& Noble, W. (2004). The speech, spatial and qualities of hearing scale (SSQ). International Journal of Audiology, 43(2), 85-99.

Gfeller, K., Jiang, D., Oleson, J. J., Driscoll, V., Olszewski, C., Knutson, J. F., et al. (2012). The effects of musical and linguistic components in recognition of real-world musical excerpts by cochlear implant recipients and normal-hearing adults. Journal of Music Therapy, 49(1), 68-101.

Gifford, R. H. (2019). Bimodal hearing: How to optimize bimodal fitting. The Hearing Journal, 72(2), 10, 12, 13.

Gifford, R. H., Dorman, M. F., Shallop, J. K., \& Sydlowski, S. A. (2010). Evidence for the expansion of adult cochlear implant candidacy. Ear and Hearing, 31(2), 186-194.

Harris, M. S. \& Hay-McCutcheon, M. (2010). An analysis of hearing aid fittings in adults using cochlear implants and contralateral hearing aids. The Laryngoscope, 120(12), 2484-2488.

Hua, H., Johansson, B., Jönsson, R., \& Magnusson, L. (2012). Cochlear implant combined with a linear frequency transposing hearing aid. Journal of the American Academy of Audiology, 23(9), 722-732.

Keilmann, A. M., Bohnert, A. M., Gosepath, J., \& Mann, W. J. (2009). Cochlear implant and hearing aid: A new approach to optimizing the fitting in this bimodal situation. European Archives of Oto-Rhino-Laryngology, 266(12), 1879-1884.

Kong, Y. Y. \& Carlyon, R. P. (2007). Improved speech recognition in noise in simulated binaurally combined acoustic and electric stimulation. The Journal of the Acoustical Society of America, 121(6), 3717-3727.

Kong, Y. Y., Cruz, R., Jones, J. A., \& Zeng, F. G. (2004). Music perception with temporal cues in acoustic and electric hearing. Ear and Hearing, 25(2), 173-185.

McDermott, H. (2011). Benefits of combined acoustic and electric hearing for music and pitch perception. Seminars in Hearing, 32(1), 103-114.

McDermott, H. \& Henshall, K. (2010). The use of frequency compression by cochlear implant recipients with postoperative acoustic hearing. Journal of the American Academy of Audiology, 21(6), 380-389.

Messersmith, J. J., Jorgensen, L. E., \& Hagg, J. A. (2015). Reduction in highfrequency hearing aid gain can improve performance in patients with contralateral cochlear implant: A pilot study. American Journal of Audiology, 24(4), 462-468.

Moher, D., Shamseer, L., Clarke, M., Ghersi, D., Liberati, A., Petticrew, M., et al. (2015). Preferred reporting items for systematic review and metaanalysis protocols (PRISMA-P) 2015 statement. Systematic Reviews, 4(1), 1 .

Müller, J., Brill, S., Hagen, R., Moeltner, A., Brockmeier, S. J., Stark, T., et al. (2012). Clinical trial results with the MED-EL fine structure processing coding strategy in experienced cochlear implant users. ORL; Journal for Oto-rhino-laryngology and its Related Specialties, 74(4), 185-198.
Neuman, A. C. \& Svirsky, M. A. (2013). Effect of hearing aid bandwidth on speech recognition performance of listeners using a cochlear implant and contralateral hearing aid (bimodal hearing). Ear and Hearing, 34(5), 553-561.

Neuman, A. C., Zeman, A., Neukam, J., Wang, B., \& Svirsky, M. A. (2019). The effect of hearing aid bandwidth and configuration of hearing loss on bimodal speech recognition in cochlear implant users. Ear and Hearing, 40(3), 621-635.

Oticon. (2016). Bimodal Hearing Aid Fitting Guidelines. Retrieved from https://www.oticon.nl/-/media/oticon/main/pdf/master/bimodal/22596 uk_wp_bimodal_fitting_h2_2016.pdf?la=nl-nl.

Park, L. R., Teagle, H. F. B., Buss, E., Roush, P. A., \& Buchman, C. A. (2012). Effects of frequency compression hearing aids for unilaterally implanted children with acoustically amplified residual hearing in the nonimplanted ear. Ear and Hearing, 33(4), e1-el2.

Perreau, A. E., Bentler, R. A., \& Tyler, R. S. (2013). The contribution of a frequency-compression hearing aid to contralateral cochlear implant performance. Journal of the American Academy of Audiology, 24(2), 105120.

Shannon, R. V., Zeng, F. G., Kamath, V., Wygonski, J., \& Ekelid, M. (1995). Speech recognition with primarily temporal cues. Science, 270(5234), 303-304.

Siburt, H. W. \& Holmes, A. E. (2015). Bimodal programming: A survey of current clinical practice. American Journal of Audiology, 24(2), 243-249.

Spahr, A. J., Dorman, M. F., Litvak, L. M., Van Wie, S., Gifford, R. H., Loizou, P. C., et al. (2012). Development and validation of the AzBio sentence lists. Ear and Hearing, 33(1), 112-117.

UK Cochlear Implant Study Group. (2004). Criteria of candidacy for unilateral cochlear implantation in postlingually deafened adults II: Costeffectiveness analysis. Ear and Hearing, 25(4), 336-360.

Ullauri, A., Crofts, H., Wilson, K., \& Titley, S. (2007). Bimodal benefits of cochlear implant and hearing aid (on the non-implanted ear): A pilot study to develop a protocol and a test battery. Cochlear Implants International, 8(1), 29-37.

Veugen, L. C. E., Chalupper, J., Snik, A. F. M., van Opstal, A. J., \& Mens, L. H. M. (2016a). Frequency-dependent loudness balancing in bimodal cochlear implant users. Acta Oto-Laryngologica, 136(8), 775-781.

Veugen, L. C. E., Chalupper, J., Snik, A. F. M., van Opstal, A. J., \& Mens, L. H. M. (2016b). Matching automatic gain control across devices in bimodal cochlear implant users. Ear and Hearing, 37(3), 260-270.

Vroegop, J. L., Goedegebure, A., \& van der Schroeff, M. P. (2018). How to optimally fit a hearing aid for bimodal cochlear implant users: A systematic review. Ear and Hearing, 39(6), 1039-1045.

Vroegop, J. L., Homans, N. C., van der Schroeff, M. P., \& Goedegebure, A. (2019). Comparing two hearing aid fitting algorithms for bimodal cochlear implant users. Ear and Hearing, 40(1), 98-106.

Yehudai, N., Shpak, T., Most, T., \& Luntz, M. (2013). Functional status of hearing aids in bilateral-bimodal users. Otology and Neurotology, 34(4), 675-681.

Zhang, T., Dorman, M. F., Gifford, R., \& Moore, B. C. J. (2014). Cochlear dead regions constrain the benefit of combining acoustic stimulation with electric stimulation. Ear and Hearing, 35(4), 410-417. 